\title{
A CARREIRA E A AVALIAÇÃO DOS PROFESSORES EM PORTUGAL: mudanças nos modos de regulação da educação
}

\author{
Sofia Viseu \\ Instituto de Educação, Universidade de Lisboa \\ João Barroso \\ Instituto de Educação, Universidade de Lisboa
}

\begin{abstract}
Resumo
As modalidades de ingresso e de progressão na carreira constituíram os principais fatores condicionantes do exercício da profissão docente, no ensino público, em Portugal nas últimas décadas. A sua evolução marcou decisivamente as políticas educativas e constitui um aspeto significativo da alteração dos modos de regulação do sistema educativo. No presente artigo iremos começar por descrever e analisar aspetos dominantes dessa evolução, nos domínios do recrutamento, do ingresso e da progressão na carreira e na avaliação dos professores do ensino público, sobretudo na última década. Em seguida, iremos sistematizar a informação obtida, para pôr em evidência algumas das controvérsias atuais que afetam o exercício da profissão docente nesses domínios. Finalmente, iremos propor linhas interpretativas que situam a evolução descrita no contexto das mudanças em curso dos processos de regulação da educação, em Portugal.
\end{abstract}

Palavras-chave: profissão docente; políticas educativas; regulação da educação

\begin{abstract}
In the last decades, initial entry, recruitment and career-based systems were the main conditioning factors of the teacher' work in public education in Portugal. Its evolution has decisively shaped education policy and is a relevant factor of the change in the modes of regulation of the education system. In this article, we will describe and analyses the dominant aspects of this evolution, regarding initial entry, recruitment, career and evaluation of public school teachers, especially in the last decade. Then, we will systematize the information obtained, to highlight some of the current controversies that affect the exercise of the teaching profession in these areas. Finally, we will propose interpretive lines that situate the evolution described in the context of the ongoing changes in education governance in Portugal.
\end{abstract}

Keywords: teaching profession; education policy; education governance 


\section{Introdução}

O presente texto constitui uma síntese interpretativa sobre a intervenção das autoridades públicas na definição da carreira e da avaliação dos professores em Portugal e sobre o seu significado, à luz das mudanças na regulação política e social da educação. Esta síntese tem por base uma pesquisa centrada nas iniciativas legislativas levadas a cabo pelas autoridades públicas portuguesas no que se refere aos professores, em particular, durante a última década ${ }^{1}$. Nessa investigação recorreu-se essencialmente à pesquisa arquivística, através da consulta e análise de documentos oficiais da administração educativa, incluindo o Diário da República e o Diário da Assembleia da República, despachos, pareceres, relatórios do Conselho Nacional de Educação e registos de estatísticas oficiais do Ministério da Educação². Foi ainda mobilizada investigação produzida em Portugal sobre políticas públicas e a profissão docente, designadamente através de publicações e teses de doutorado que se têm dedicado ao tema nos últimos anos. Houve também a consulta a fontes da comunicação social para esclarecer alguns modos de produção e de receção das medidas políticas em análise. A pesquisa centrou-se nos professores do segundo e do terceiro ciclos do ensino básico e do ensino secundário, excluindo docentes com grupos de recrutamento específicos, como o caso dos docentes de educação especial.

Para interpretar as transformações ocorridas e as suas perspetivas de evolução mobilizou-se a reflexão realizada sobre as reformas recentes na administração da educação no quadro da transformação dos processos de regulação (BARROSO, 2018).

O artigo está organizado em três pontos. No primeiro ponto, de natureza descritiva e diacrónica, iremos apresentar a evolução das políticas educativas dos últimos anos que visam, por um lado, os processos de recrutamento e o ingresso na carreira docente, e por outro, a avaliação de desempenho e a progressão na carreira dos professores. No segundo ponto, apresentaremos, a título de exemplo, as mudanças previstas sobre o recrutamento e indução da carreira profissional para, de seguida, propormos uma visão compreensiva e interpretativa sobre as principais mudanças nas políticas que visam a profissão docente. Finalmente, num terceiro ponto, procuraremos atender aos possíveis efeitos e sentidos da evolução anteriormente referida, no quadro das alterações dos modos de regulação do sistema educativo e das políticas educativas.

\section{A carreira dos professores e a avaliação de desempenho em Portugal}

A regulamentação da carreira e a definição do processo de avaliação dos professores constituem dois dos instrumentos mais significativos do condicionamento legislativo da profissão docente, em Portugal. Apesar de estarem associados, foram objeto de medidas distintas e a avaliação do desempenho, mais tardia, passou a ter uma função específica na gestão do percurso profissional dos professores. Assim, num primeiro momento, iremos analisar três aspetos essenciais que marcam a evolução recente do sistema de ingresso e da progressão na carreira docente. Depois, num segundo momento, iremos descrever a evolução 
recente das medidas de avaliação do desempenho e a sua influência na progressão da carreira dos professores.

\section{A carreira}

Ao longo das últimas décadas, e desde a publicação do primeiro Estatuto da Carreira Docente (ECD) em 1990, a produção normativa sobre o recrutamento foi sofrendo várias alterações, sendo importante sinalizar três aspetos que marcam esta evolução: o aumento das qualificações exigidas para o ingresso na carreira; a permanência de um processo centralizado de recrutamento dos docentes; a subsistência, durante a última década, de um valor médio de $20 \%$ de professores contratados.

O primeiro aspeto está relacionado com o progressivo aumento das exigências de qualificações para ingressar na carreira docente. A Lei de Bases do Sistema Educativo de 1986 estabeleceu que a qualificação para a docência era diferenciada quanto ao grau de ensino: para educadores de infância e professores do $1^{\circ}$ ciclo do ensino básico bastava o bacharelato (3 anos) e os professores dos $2^{\circ}$ e $3^{\circ}$ ciclos do ensino básico e do ensino secundário deviam ser detentores de licenciatura (5 anos). No início dos anos 1990, o primeiro ECD, estabeleceu duas categorias na carreira docente a que chamou professores e docentes. Os professores possuíam apenas habilitação própria ou habilitação suficiente ${ }^{3}$, ou seja, eram detentores de uma licenciatura ou de um bacharelato, sem que tivessem formação pedagógica específica; os docentes eram detentores de habilitação profissional ou, dito de outro modo, a habilitação incluía componentes de formação científica, tecnológica, técnica ou artística adequadas, mais a formação pedagógica exigida (estágio profissional).

Em 1997, uma alteração à Lei de Bases do Sistema Educativo estabeleceu que os educadores de infância e os professores dos ensinos básico e secundário deveriam possuir uma mesma qualificação profissional - licenciatura - com o fim de assegurar igual estatuto e reconhecimento profissional para os docentes de todos os níveis de ensino.

Atualmente, e desde 2014, o ingresso na carreira tem como principal requisito a obtenção do grau de mestre, em diferentes especialidades e conforme o nível de ensino, sendo a habilitação profissional para a docência entendida como “condição indispensável para o desempenho da atividade docente"4 . Esta condição foi defendida no preambulo da legislação que aprovou o regime jurídico da habilitação profissional para a docência, atendendo aos seguintes fundamentos:

«Múltiplos estudos internacionais recentes, divulgados tanto em publicações científicas como em análises e sínteses de organizações independentes, nomeadamente a OCDE e a Eurydice, têm vindo a revelar que o aumento do nível geral da formação de professores tende a ter um efeito mensurável e muito significativo na qualidade do sistema de ensino, tal como se registou notavelmente na Finlândia. Têm igualmente vindo a indicar que a profundidade do conhecimento dos professores sobre as matérias específicas que lecionam tem efeito expressivo na sua autonomia e segurança em sala de aula, traduzindo-se 
numa mais elevada qualidade da aprendizagem dos alunos (...). Importa pois, numa lógica incremental, reforçar instrumentos que propiciem, a médio e longo prazo, ter nas nossas escolas os mais bem preparados, mais bem treinados, mais vocacionados e mais motivados para desenvolver a nobre e exigente tarefa de ensinar» (Decreto-Lei n. ${ }^{\circ}$ 79/2014 de 14 de maio).

O aumento da exigência das qualificações para a docência obtidas através do grau académico parece ter sido relativamente consensual ${ }^{5}$ e a população docente em Portugal é atualmente a mais habilitada de sempre. De facto, o nível habilitacional dos docentes da educação pré-escolar, dos ensinos básico e secundário tem crescido de forma sustentada e constante desde 2007, com mais docentes detentores de graus académicos, nomeadamente de mestrado e doutoramento (DGEC e DSEE, 2017).

A evolução dos critérios para acesso à docência fez-se, como vimos, sobretudo com base na exigência de diferentes níveis de diplomas académicos: primeiro, distinguindo a formação dos educadores de infância e dos professores do primeiro ciclo, a quem se exigia, o bacharelato, da formação dos restantes professores a quem se exigia a licenciatura; depois passou a ser obrigatória a licenciatura para todos os docentes e mais recentemente o mestrado.

Contudo, importa registar que, em 2007, quando foi aprovado um novo ECD, o ingresso dos docentes na carreira dependia, para além das habilitações académicas e da abertura de vagas, da aprovação dos candidatos numa prova de avaliação de conhecimentos e capacidades (PACC). Esta prova estava organizada em função dos programas e das orientações curriculares dos diferentes graus de ensino e a sua principal finalidade era apurar se o candidato possuía os conhecimentos e competências necessárias à atividade docente, numa determinada área de especialidade.

Inicialmente, a prova deveria ser feita por todos os professores contratados, como condição para concorrem ao concurso nacional de professores, mas acabou por ser apenas aplicada durante dois anos aos docentes com menos de cinco anos de serviço, tendo sido suspensa definitivamente em 2015. Este recuo das autoridades públicas resultou de uma enorme onda de contestação por parte dos professores e, sobretudo, por ter sido declarada inconstitucional por um acórdão do Tribunal de Contas, após pedido de fiscalização por parte dos sindicatos de professores. Um dos fundamentos da decisão incluía o pressuposto que a certificação das instituições do ensino superior devia ser considerada suficiente para assegurar a preparação dos professores, dispensando-se assim a necessidade de proceder a uma outra avaliação das suas capacidades.

O segundo aspeto que importa realçar sobre a evolução do ingresso na carreira está relacionado com a centralização desse processo, através de um concurso nacional anual, promovido para todo o território, pelos serviços do Ministério da Educação. A definição da esmagadora maioria das vagas para a colocação de professores em Portugal cabe à administração central, através de concursos públicos, para os chamados "quadros de escola”, destinados a cobrir necessidades permanentes das escolas estabelecidas pelo Ministério da Educação. Nesse processo, os serviços do Ministério asseguram praticamente todos os procedimentos para a concretização do concurso, incluindo: “a fixação de vagas dos quadros 
e das necessidades transitórias, a abertura do concurso, a conceção de formulários para o concurso, a validação, em ligação com outros serviços, de dados dos candidatos, a realização do concurso, a ordenação e colocação dos candidatos, a decisão sobre as reclamações, entre outras” (MORAIS, 2016, p. 126-127).

Atualmente, a colocação de professores está organizada num concurso anual de duas fases: um concurso externo, no qual podem concorrer todos os professores, a nível nacional, com vista à integração nos quadros (no caso de professores que já se encontrem efetivos ${ }^{6}$, este concurso serve para aqueles que desejam mudar de escola); e um concurso interno, destinado à mobilidade dos que ficaram colocados no concurso externo. Os principais critérios para a colocação consistem, prioritariamente, no tempo de serviço docente, a classificação do grau académico e a menção da avaliação de desempenho docente.

De assinalar ainda que durante a década de 1990 foram existindo outras modalidades de recrutamento e ingresso na carreira docente mais desconcentradas, como, por exemplo, os concursos de provimento e afetação, os "mini concursos" e concursos de âmbito regional. Atualmente existem modalidades concursais onde as escolas desempenham um papel mais ativo na seleção e recrutamento dos candidatos, nomeadamente: em escolas inseridas em Territórios Educativos de Intervenção Prioritária, escolas com contratos de autonomia ou em escolas cuja oferta escolar inclui Cursos de Educação e Formação para Adultos ou Cursos de Educação e Formação. Nestes casos, são as escolas que abrem concursos para determinados contingentes que respondam a necessidades específicas das suas ofertas e projetos, recrutando e seriando diretamente os professores. Contudo, e excetuando estes casos, desde 2003, os concursos de professores “mais desconcentrados” foram extintos, com o argumento da desburocratização dos processos e pelo desejo em conferir aos processos de recrutamento uma transparência acrescida.

A opção por um processo de recrutamento predominantemente centralizado tem sido defendida pela administração central e pelos sindicatos. No primeiro caso, por se entender que ela é a mais capacitada para garantir maior objetividade e rigor nos procedimentos, assegurando um maior controlo sobre o processo. No segundo caso, por considerarem que assim se garante maior transparência nos processos e condições de igualdade no acesso, facilitando a capacidade de negociação (MORAIS, 2016). Vale a pena referir que esta opção contraria a tendência dominante na generalidade dos países europeus onde vigoram sistemas de recrutamento aberto, isto é, processos de recrutamento descentralizados, ou nas escolas, ou em autoridades regionais ou locais (Comissão Europeia/EACEA/Eurydice, 2013a).

$\mathrm{O}$ terceiro aspeto a referir sobre o ingresso na carreira de professor diz respeito à subsistência, durante a última década, de um valor médio de $20 \%$ de professores contratados, ou seja, professores com contratos individuais de trabalho renováveis, ou não, a cada ano, em função da sua posição no concurso externo. O gráfico dá conta da variação de docentes do quadro e contratados no ensino público, na última década. 
Evolução do número de docentes do quadro e contratados no ensino público entre 2007/08 e 2016/17.

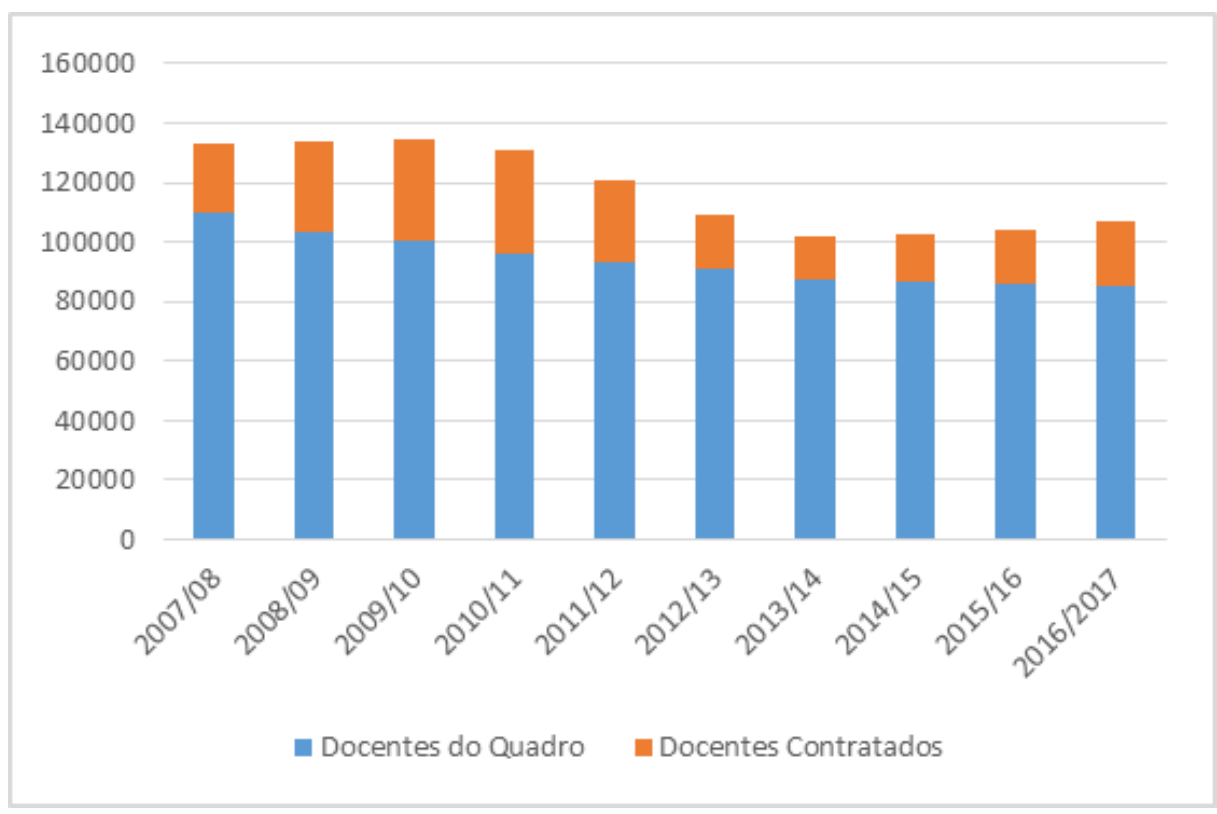

Fonte: DGEC e DSEE.

Apesar de verificarmos algumas oscilações (com um maior número de professores contratados entre 2010 e 2012 que coincidiu com o período de intervenção da Troika $a^{7}$ ), o que parece ser mais relevante registar é que a relação entre o número de professores do quadro e os professores contratados se tem mantido mais ou menos constante.

Mais recentemente, em 2014, para cumprir uma diretiva europeia foi criada uma norma (designada "norma-travão") que impede a utilização abusiva dos contratos a prazo e que obriga a abertura de vagas para os professores que tenham três anos de contratos sucessivos ${ }^{8}$. Como resultado, houve um aumento do número de professores que entraram para os quadros de escola, mas foi observado "um conjunto de bloqueios capazes de lhe retirar efeito prático" (MEIRA, 2017, p. 101). Este fenómeno esteve associado ao uso de plataformas eletrónicas, através das quais se processava a contratação, que continham “dispositivo[s] redutor[es]” e que, na prática, dificultavam a admissão ao concurso de professores que reuniam as condições previstas na norma (idem, p. 101).

\section{Avaliação de desempenho}

O processo de avaliação de desempenho constitui um elemento importante da regulação da carreira docente tendo sofrido várias alterações, ao longo das 16 revisões do ECD 
efetuadas desde a sua aprovação inicial em 1990. Quando analisadas em detalhe, encontramos nestas alterações uma considerável complexidade, com avanços e recuos nos normativos legais e com uma assinável contestação social, a que se seguiram momentos de intensa negociação. As mudanças efetuadas traduzem uma crescente complexificação e exigência dos procedimentos, assim como uma crescente conexão e interdependência da avaliação com a progressão na carreira. É esse processo que iremos descrever sucintamente em seguida.

Desde o início da década de 1990 a progressão na carreira docente está condicionada pela avaliação de desempenho, fazendo depender a primeira dos resultados da segunda. Conforme se pode ler no preambulo do decreto que regulamentou esta medida:

“[Uma] inovação de fundo [desta legislação] consiste na consagração da necessidade da avaliação do desempenho dos docentes, com vista à melhoria da respetiva atividade profissional e à sua valorização aperfeiçoamento individual, da qual passa a depender a progressão na carreira” (Decreto-Lei n. ${ }^{0} 139-A / 90$, de 28 de abril).

Durante a década de 1990 e meados dos anos 2000, a progressão na carreira docente baseou-se, essencialmente, na contagem do tempo de serviço e na obtenção de créditos de formação contínua e num relatório de autoavaliação. Tratava-se de uma "carreira única” e, cumprindo os requisitos definidos, seria possível atingir o topo da carreira remuneratória. Em 1998, foram introduzidas alterações na avaliação do desempenho, complexificando os processos, muito em particular, no que se refere às menções qualitativas e à introdução de um sistema de bonificações para os docentes que possuam melhor avaliação de desempenho.

Em 2007, com a publicação de um novo ECD, o processo de avaliação e as condições de progressão da carreira foram substancialmente alteradas, em particular, nos seguintes aspetos: a criação de categorias hierarquizadas ("professores titulares" e "professores"9) condicionando o acesso ao topo da carreira; a implementação de um sistema de avaliação dos professores cuja classificação estaria sujeita a uma quota que dependeria dos resultados obtidos na avaliação externa da escola; a introdução de novas dimensões na avaliação que, para além do relatório de autoavaliação, passou a incluir a observação de aulas e a criação de novas e mais precisas menções da avaliação de desempenho.

Estas opções foram justificadas (na legislação em causa) como forma de tornar a avaliação de desempenho "mais exigente e com efeitos no desenvolvimento da carreira”, no sentido de "promover e premiar o mérito e valorizar a atividade letiva". Visava-se, assim, romper com o modelo de avaliação e progressão em vigor, considerando-se que "com raras exceções” se havia convertido "num simples procedimento burocrático, sem qualquer conteúdo".

É importante assinalar que esta alteração do modelo de avaliação dos professores foi justificada como decorrente de um processo mais amplo de Reforma da Administração Pública. Este processo, conduziu à criação e um novo Sistema Integrado de Avaliação do Desempenho da Administração Pública iniciado em 2004 que, embora prevendo a existência 
de carreiras especiais onde se incluíam os professores, se assumia como um "sistema transversal a todos os serviços” e visava orientar os serviços públicos "para resultados, promovendo a excelência e a qualidade", diferenciando "níveis de desempenho, fomentando uma cultura de exigência, motivação e reconhecimento do mérito”.

As alterações introduzidas no modelo de avaliação dos professores provocaram uma significativa contestação e, em março de 2008, assistimos àquela que foi considerada, por muitos órgãos de comunicação social, a maior manifestação de professores até à data em Portugal $^{10}$, com a participação de 80 a 100 mil professores que se concentraram em Lisboa. Apesar disso, o novo Estatuto foi aprovado e iniciaram-se dois ciclos avaliativos de professores (2007 -2009; 2009 -2011).

Porém, em 2010, o estatuto (ECD) foi novamente alterado. Estas alterações decorreram de um processo negocial entre a administração educativa e os sindicatos de professores, através do qual foram revertidas algumas das opções introduzidas anteriormente, nomeadamente a menção à carreira de professor titular e a associação entre resultados escolares dos alunos e a avaliação de desempenho dos docentes (cf. Acordo de Princípios para a Revisão do Estatuto da Carreira Docente e do Modelo de Avaliação dos Professores dos Ensinos Básico e Secundário e dos Educadores de Infância de 2010).

De facto, após este processo negocial, foi publicado um novo ECD que reviu alguns dos artigos anteriores, mas manteve como "objetivos essenciais garantir uma efetiva avaliação do desempenho docente com consequências na carreira e a valorização do mérito”. A legislação que se seguiu, e que está atualmente em vigor, não trouxe alterações substanciais quando à estabilização de um modelo de avaliação baseado em múltiplas fontes de evidência e restritivo quando à possibilidade de obter as classificações máximas no processo de avaliação (em virtude da adoção de quotas). Na realidade, este modelo de avaliação tornou mais lenta e restringiu a progressão na carreira (NUNES E RODRIGUES, 2011). Ainda assim, após esta fase inicial de “resistência à avaliação”, temos assistido a uma progressiva aceitação e normalização do processo de avaliação do desempenho (JACINTO, 2013).

\section{Mudanças nas políticas que visam a profissão docente}

Apesar da evolução descrita anteriormente, a situação em que se encontra a profissão docente tem vindo a degradar-se e os apelos à mudança fazem-se sentir. Esta necessidade de mudança nas formas e nas condições de trabalho dos professores é tanto maior quanto as alterações recentemente introduzidas ao nível da descentralização da administração e da autonomia dos estabelecimentos de ensino vieram aumentar as suas responsabilidades. As normas previstas para o recrutamento e para o papel da indução na carreira dos professores, que iremos analisar de seguida, são um bom exemplo desta mudança considerada necessária. Mas estas mudanças indiciam, também, modificações mais profundas no contexto político em que se regula a educação, como iremos ver a propósito de duas hipóteses de interpretações que apresentaremos na continuidade desta reflexão. 


\section{As mudanças no processo de recrutamento}

Um dos aspetos onde mais se faz sentir o desejo de mudança na regulamentação da profissão docente, em Portugal, prende-se com as normas do recrutamento. Estas normas têm um efeito estruturante sobre o percurso profissional dos professores e, indiretamente, sobre a sua formação inicial e contínua.

A situação em Portugal é influenciada pelo que se passa na União Europeia, como o demonstra o recente relatório elaborado pela Eurydice sobre esta matéria (Comissão Europeia/EACE/ Eurydice, 2018). De acordo com este relatório (p. 10), na maior parte dos sistemas educativos europeus (cerca de 75\%) a responsabilidade de recrutar os professores é descentralizada e cabe ou às autoridades locais, ou às escolas que fazem também a gestão das vagas disponíveis. Contudo, num número reduzido de países ainda subsiste "um procedimento concursal organizado por autoridades de nível superior” (idem, p.39), como acontece, na maior parte dos casos, em Portugal. Conforme é indicado pelo Relatório que temos estado a citar (idem, p. 18), a seleção e o recrutamento de novos professores, na Europa, não se devem fazer unicamente em função do grau académico, mas também em função de um conjunto mais vasto de atitudes e de aptidões. É necessário promover um equilíbrio de género no corpo docente, bem como, criar condições contratuais e de emprego que garantam a progressão salarial, o desenvolvimento profissional contínuo, o trabalho em equipa e a formação por pares.

Quanto às condições exigidas para a aceder à profissão, elas repartem-se entre a conclusão da formação inicial para a docência (cerca de metade dos países da União Europeia) e a necessidade de cumprir exigências suplementares, como seja, realizar um exame competitivo no final do período de indução (European Union, 2019, p.27). Convém notar que existem já dez países europeus (entre os quais Portugal) onde é exigida formação inicial a nível de mestrado, para ensinar no primeiro ciclo, mas são cerca de metade, os países europeus onde é exigida a mesma formação, para ensinar no ensino secundário superior (como é igualmente o caso de Portugal) (idem, p. 24).

Um dos elementos que traduz uma clara especificidade das condições de recrutamento para a profissão docente tem que ver com o elevado número de mulheres, a nível da União Europeia: 95,8\% no pré-escolar; 85,5\% no ensino primário; e 64,7\% no ensino secundário. Entre as várias razões para este estreitamento no recrutamento está a baixa atratividade da profissão de professor o que, juntamente com o estereótipo de género, explica a elevada percentagem de mulheres (idem, p. 22)

A situação existente em Portugal, neste domínio, está na origem da solicitação feita pela Assembleia da República ao Conselho Nacional de Educação para elaborar um estudo sobre o "regime de seleção e recrutamento do pessoal docente da educação pré-escolar e dos ensinos básico e secundário” (Conselho Nacional de Educação, 2018). Esse estudo teve por principal objetivo responder a uma diminuição acentuada da atratividade da profissão que se manifesta, sobretudo, na redução da procura, nas queixas repetidas dos professores sobre as 
condições de exercício da profissão e na persistência de um regime centralizado de seleção e recrutamento.

De acordo com as próprias conclusões do relatório, em Portugal, o acesso à carreira de educador e de professor dos ensinos básico e secundário faz-se através de concursos nacionais centralizados, controlados pelas instituições de formação, através de um processo complexo. A possibilidade de seleção é residual porque o sistema de recrutamento, apesar de transparente, não diferencia os candidatos nem responde às necessidades das escolas com projetos singulares. Quando comparada a situação existente em Portugal com o que se passa na maior parte dos países europeus, o Relatório conclui haver bastantes semelhanças, nomeadamente: a exigência de um diploma de formação inicial para acesso à carreira; a posse do estatuto de funcionário público; a valorização do desenvolvimento profissional contínuo; a definição de um quadro de competências comum; a existência de uma carreira hierárquica com diferentes níveis. De assinalar ainda, conforme o Relatório também regista, que existem alguns países com regulamentações diferentes em vários domínios, mas não são dominantes.

Finalmente, são propostos pelos autores do Relatório "três cenários possíveis para a seleção e recrutamento de docentes" que podem existir separadamente ou de forma combinada. Um cenário A, onde se integra o caso português, que se caracteriza pelo facto de o recrutamento ser feito a nível central, com recurso a uma lista graduada. Um cenário B em que os professores são selecionados em função de um determinado perfil, de acordo com o projeto educativo municipal ou de escola. Um cenário $\mathrm{C}$, em que os candidatos são selecionados ao nível de cada escola, em função de critérios próprios.

\section{A indução profissional}

Importa ainda referir a importância da primeira fase da carreira, após a formação inicial (período probatório), que deve ser objeto de um programa de apoio ao exercício da prática profissional, conhecido pelo nome de indução. Este programa existe praticamente em todos os países europeus, sendo na maior parte dos casos obrigatório. Conforme é assinalado em Comissão Europeia/EACEA/Eurydice (2018, p. 11), a indução pode revestir-se de várias formas (mentorado, desenvolvimento profissional, aprendizagem pelos pares, apoio do diretor) e é objeto de uma avaliação, com o fim de verificar se os professores adquiriram as competências práticas necessárias para trabalharem de forma independente. Esta avaliação pode servir de base a um processo formal e global de certificação das competências docentes.

A investigação tem mostrado que o apoio dado aos jovens professores, nesta fase da carreira, tem uma influência positiva na sua permanência na profissão, no desenvolvimento de práticas de ensino e nos resultados escolares dos alunos (European Union, 2019, p. 21). Como diz este relatório,

«Programas de iniciação e orientação nos estágios iniciais das carreiras permitem que os professores desenvolvam habilidades profissionais e vínculos frutíferos no ambiente escolar. Uma indução de alta qualidade com experiência em sala de aula, boas oportunidades de treinamento profissional e métodos de avaliação focados 
nas necessidades de desenvolvimento dos professores foram identificados como três elementos de política comum em países onde os resultados da aprendizagem são bons.» (idem, p. 30)

Segundo o mesmo relatório (p. 30) é frequente a utilização do mentorado nos programas de indução. O mentor é normalmente um professor sénior que presta apoio pessoal, social e profissional, apresenta os novos professores aos colegas e dá conselhos quando necessário. O mentorado é uma componente obrigatória em todos os programas de indução, exceto na Irlanda onde é opcional.

Em Portugal, ao contrário do que acontece em outros países europeus, não existe, um programa de formação específica para o início da carreira, mas tão só a exigência do candidato "fazer prova” de que preenche as condições necessárias ao exercício da profissão:

“(...) a nomeação definitiva em lugar do quadro está dependente da conclusão do período probatório (de um ano) com avaliação de desempenho igual ou superior a bom (...) [mas] apesar deste requisito, a maioria dos docentes $(72 \%$ em 2018/2019) fica dispensada da realização do período probatório, porque quando acedem ao lugar de quadro já têm vários anos de serviço.” (Conselho Nacional de Educação, 2018, p. 59).

A existência de um verdadeiro período de indução para apoio aos professores, no início da carreira, já tinha sido apresentada pelo Conselho Nacional de Educação que numa recomendação recente, intitulada Qualificação e valorização de educadores e professores dos ensinos básico e secundário (Conselho Nacional de Educação, 2019), propunha que

“(...) se substitua o período probatório por um verdadeiro ano de indução, ou seja, um ano letivo completo de exercício profissional, apoiado continuadamente pelo departamento curricular da escola, através de um docente do mesmo grupo de recrutamento e com experiência profissional de reconhecida qualidade.”

Este período inicial, a que Nóvoa (2019, p. 200) chama de “um tempo entre-dois, entre o fim da formação e o princípio da profissão (...) é fundamental no modo como nos tornamos professores, no modo como vamos viver a nossa vida no ensino” (idem, p. 201). É através dele que se realiza a “indução profissional” que, para ter êxito,

“(...) exige que os três vértices do triângulo - as instituições universitárias de formação de professores, as políticas educativas e os professores de educação básica - estejam presentes e articulados de forma sólida e equilibrada.” (idem, p. 201).

Reconhecendo a importância capital deste período, António Nóvoa propõe num interessante artigo da revista Currículo sem Fronteiras que temos estado a citar, um ensaio sobre três ambientes que encontramos nos primeiros anos de exercício profissional. Como diz na conclusão deste artigo: 
"Uma nova concepção da formação de professores deve privilegiar este tempo entre-dois, a indução profissional (...) um tempo que é estruturante do desenvolvimento profissional docente. Para o fazer é imprescindível construir sínteses e alternativas que nos permitam escapar a dicotomias e binarismos promovendo:

- a construção de um terceiro lugar institucional, lugar de coordenação interna das universidades e de articulação externa com as redes escolares, reforçando assim os processos de formação docente;

- o reconhecimento da importância do terceiro género de conhecimento, essencial para afirmar os saberes dos professores e para dar sentido e conteúdo a uma formação profissional de nível universitário;

- a necessidade de reforçar a profissão docente, dando corpo a uma terceira presença colectiva, dos professores, na formação dos seus futuros colegas e na sua integração nas escolas.” (idem, p. 207)

\section{Propostas de interpretação}

As alterações das condições de recrutamento, ingresso e avaliação dos docentes, em Portugal, analisadas anteriormente, são o reflexo de mudanças mais profundas que afetaram este grupo profissional nos últimos anos. Apresentaremos, de seguida, duas linhas interpretativas para explicar esta relação.

Uma primeira linha interpretativa está relacionada com a existência de uma certa “desvalorização social da profissão” docente, conforme é designado num relatório do Conselho Nacional da Educação (Conselho Nacional de Educação, 2016). É preciso notar que o tema da desvalorização social da profissão docente tem estado presente na agenda social, política e científica (nacional e internacional) de forma mais ou menos recorrente nos últimos anos (ver, por exemplo, BARROSO, 2003; NÓVOA, 2019). Olhando para o atual cenário português dois dados confirmam esta tendência: a) em 2009 os candidatos ao concurso de professores foram cerca de 50000 e em 2018 não chegaram aos 29 000; considerando que não tem havido um aumento do número de docentes efetivos do quadro das escolas, este dado significa uma acentuada quebra na procura da profissão; b) "apenas $2 \%$ dos jovens portugueses que realizaram os últimos testes PISA pretendem ser professores (...), sendo que esses são também os que têm baixas classificações em literacia e matemática” (Conselho Nacional de Educação, 2016, p. 4), o que mostra a reduzida atratividade da profissão, em particular junto dos alunos com melhores performances nesses testes (Comissão Europeia/EACEA/Eurydice, 2018).

Estes dados podem sinalizar possíveis resultados de algumas medidas que visam a profissão docente em Portugal nos últimos anos.

Em primeiro lugar, poderão ser um dos efeitos das modalidades de recrutamento em curso que se têm mostrado incapazes de captar novos docentes, sobretudo os mais novos, 
assim como de aumentar os professores com contrato definitivo nos quadros das escolas (SILVA BODIÃO \& FORMOSINHO, 2010; ESTEVES ET AL, 2015).

Em segundo lugar, esta desvalorização social e a menor atratividade da profissão poderá decorrer das condições efetivas e da perceção das condições do trabalho docente. Para tal, contribuiu certamente a intensificação do trabalho docente, resultante do aumento do número de alunos por turma, do alargamento do seu horário de trabalho e da concretização de um leque progressivamente mais amplo de tarefas não pedagógicas, nomeadamente administrativas e de avaliação. Num estudo recente em que se realizou um inquérito por questionário a cerca de 3000 professores, 98,8\% dos docentes considerou que, nos últimos anos da sua atividade profissional, o volume de trabalho aumentou, sendo que praticamente $60 \%$ dos inquiridos considerou que aumentou muito (AZEVEDO Et al, 2016). O mesmo estudo relevou ainda que $98,2 \%$ dos docentes consideraram que houve um aumento do volume das tarefas burocráticas e administrativas (idem). Para além desta intensificação do trabalho docente, a questão da sua avaliação de desempenho merece uma menção especial. Conforme assinala Flores (2009), houve uma crescente aproximação dos seus propósitos sumativos "baseados na prestação de contas e orientados para decisões de gestão de carreira" e não tanto em "propósitos formativos (orientados para o desenvolvimento profissional)" (idem, p. 242). Apesar da aceitação das alterações que decorreram nos processos de avaliação de desempenho dos professores, mantiveram-se "atitudes de resistência ativa e passiva”, visíveis também à escala micro-organizacional (JACINTO, 2013, p. 417).

A perceção da intensificação do trabalho docente está em linha com resultados obtidos noutras geografias (DAY, 2007; Comissão Europeia/EACEA/Eurydice, 2013b; HARGREAVES, 2004; MAROY, 2006). Tal como tem vindo a ser reportado noutros países (ver, por exemplo, MONTGOMERY \& RUPP, 2005; MALET, 2009; ASSUNÇÃO \& OLIVEIRA, 2009; LIU \& ONWUEGBUZIE, 2012; SKAALVIK, \& SKAALVIK, 2016; WORTH \& VAN DEN BRANDE, 2019), a investigação tem vindo a dar conta da existência de fenómenos de stress, desmotivação e de burnout na população docente portuguesa (ver, por exemplo, RUIVO et al, 2008; POCINHO E CAPELO, 2009; GOMES et al, 2012).

Enfim, as modalidades de recrutamento e de ingresso na carreira, assim como a intensificação do trabalho docente parecem ter como possíveis efeitos a desvalorização social da profissão. Contudo, as medidas que visam a profissão docente aqui descritas, devem ser compreendidas num plano mais amplo que não se esgota nas políticas educativas, o que nos conduz à segunda linha interpretativa.

Uma segunda linha interpretativa prende-se com a produção de uma necessária e mais cautelosa apreciação das mudanças que se produziram na profissão docente. É certo que se analisarmos em detalhe e ao pormenor a evolução das medidas que visam esta profissão, vemos diferentes tendências, conceções, tensões, avanços e recuos, a diversos tempos. No entanto, numa perspetiva mais ampla, é importante sublinhar que estas medidas foram desencadeadas em cenários de contenção orçamental e no quadro de processos de reforma da administração pública portuguesa, que têm vindo a ganhar forma sob o signo da Nova Gestão Pública (NGP) (VERGER E NORMAND, 2015). Neste ponto vale a pena sublinhar a crescente exigência e complexificação da avaliação de desempenho, como um bom exemplo 
de um sinal da regulação transnacional e da influência que a NGP tem nas políticas educativas (COSTA, 2007; PEREIRA, 2009). Mas é preciso notar que, embora dirigidas aos professores, as mudanças em curso contemplaram todos os servidores públicos. Simultaneamente, se atenderemos ao que sucedeu com os diretores escolares onde aconteceram mudanças rápidas e profundas, seja no plano das responsabilidades, seja no plano das funções, seja ainda no plano dos papéis auto percecionados (VISEU E CARVALHO, 2018), podemos tender a relativizar a profundidade das mudanças introduzidas na profissão docente.

Em parte, esta relativização justifica-se também pela considerável capacidade de mobilização e de intervenção dos sindicatos dos professores que se têm mostrado suficientes, para implicar a criação de movimentos de revindicação e negociação. Esta capacidade de mobilização tem sido particularmente visível, nomeadamente na comunicação social, pela contestação sobre a implementação de medidas políticas que afetam de forma direta a sua carreira docente (STOLEROFF \& PEREIRA, 2008).

\section{Mudança nos processos de regulação}

As alterações introduzidas nas condições de recrutamento, de ingresso na carreira e de avaliação dos docentes, atrás referidas, indiciam uma mudança progressiva nos processos de regulação da educação. Na verdade, estamos confrontados hoje, em Portugal como em outros países, com uma recomposição do papel do Estado na definição e provisão da educação que passa, não tanto por uma alteração da sua importância relativa, ao nível do financiamento e da garantia de recursos, mas, principalmente, por uma alteração da sua intervenção na definição, execução e controlo das políticas educativas, com graus e implicações diferentes quanto ao protagonismo estatal.

As alterações introduzidas na regulamentação da profissão docente inserem-se portanto no aparecimento destes novos modos de regulação que se caracterizam, sobretudo, pelo facto de não se basearem, como no modelo burocrático, na legitimidade da racionalidade e da lei, consideradas simultaneamente como formas de coordenação e fonte de valores. Embora não tenham ligação direta e objetiva com a profissão docente ou não sejam postos em prática com esse objetivo explícito, assumem-se, cada vez mais, como drivers das políticas educativas. São modos de regulação que acentuam o controlo a posteriori como modo preferencial de orientação da ação e que incluem, entre outros, o acréscimo da avaliação externa e da autonomia das escolas (BARROSO, 2005; MAROY \& MANGEZ, 2008).

No caso português, podemos apontar, a título de exemplo, a divulgação dos resultados das avaliações das escolas e dos resultados dos alunos nos exames de avaliação; o novo reforço da descentralização de competências em matéria de educação para as autarquias; normativos e orientações das autoridades públicas que muito recentemente foram publicados e que apontam para uma crescente flexibilidade curricular e autonomia pedagógica das escolas. Acrescentam-se ainda o desenvolvimento de novos mecanismos de controlo, baseados na avaliação das performances das escolas e da prestação de contas, muitas vezes suportados por complexas e sofisticadas plataformas informáticas (AFONSO, 2009; MEIRA, 
2017); a emergência e crescente importância de novos atores (não estatais), nacionais e supranacionais, que difundem mensagens e discursos sobre o modo como os sistemas educativos devem ser governados (CARVALHO, VISEU \& GONÇALVES, 2019).

Estas diferentes modalidades de intervenção configuram, assim, o aparecimento de novas formas de regulação chamadas de pós-burocráticas e de neo-burocráticas (BARROSO, 2013). No primeiro caso - regulação pós-burocrática - muitas destas medidas inserem-se nas estratégias que visam criar condições para uma recomposição do papel do Estado e para o aparecimento de novos modos de regulação. Entre estas medidas destacam-se as que viabilizam a criação de um mercado educativo (a autonomia das escolas destina-se a viabilizar a concorrência e a liberdade de escolha) e as que permitem promover um "estado avaliador" (a autonomia serve para justificar a aceitação da avaliação como instrumento de regulação). No segundo caso - regulação neo-burocrática - as alterações das formas de governo das escolas e da sua autonomia são orientadas para melhorarem o funcionamento burocrático da administração, face ao aumento da complexidade e da diversidade do sistema. Isto significa que é preciso mudar qualquer coisa (os aspetos morfológicos) para preservar a essência do poder e da autoridade do Estado e dos seus sistemas de controlo. Muitas vezes, as transformações da gestão das escolas justificadas pela NGP e não passam de uma modernização cosmética da administração pública ao serviço dos mesmos fins e do mesmo modelo de funcionamento.

É neste contexto que a avaliação se torna, na educação, um instrumento desejado para conciliar autonomia e responsabilidade, ou para assegurar que a descentralização da gestão não compromete o controlo da decisão. A avaliação integra, assim, um vasto conjunto de instrumentos baseados em conhecimentos, produzidos especificamente para exercerem um efeito de regulação, como sejam, por exemplo, os dispositivos de avaliação, os referenciais de competências, os contratos de autonomia, as metas de aprendizagem, as "boas práticas", etc.

Com o desenvolvimento das tecnologias de informação e comunicação, estes instrumentos estão associados ao que Williamson (2015) chama de "digital education governance" (governo digital da educação). Na verdade (segundo este autor) o governo da educação é fortemente condicionado pelo "objetivo de quantificação de toda a espécie de comportamentos humanos e sociais” ou, para utilizar a expressão divulgada por Rose (1991), entre outros, a "governação pelos números". Isto traduz-se na construção e alimentação sistemática de grandes bases de dados, com recurso às tecnologias digitais a que Williamson (2015) chama de "instrumentos de política em tempo real".

É o que acontece nas nossas escolas, onde os professores e os diretores gastam cada vez mais tempo a alimentar as mais diversas plataformas informáticas de recolha e visualização de dados online, no domínio da avaliação, da gestão de recursos, da organização de horários, etc. Esta regulação pelos instrumentos permite, assim, um controlo indireto e, muitas vezes, à distância das políticas educativas e está presente em todos os níveis (transnacional, nacional, local) sendo responsável pelo fortalecimento das tendências neo-burocráticas de que se falava atrás. 
Como alerta um documento publicado pela OCDE (2017, p. 123), a partir de informação recolhida quando da aplicação do PISA 2015, a complexidade crescente dos sistemas de ensino fez com que a delegação de poderes não possa ser vista de maneira linear, sem ter em conta a interdependência entre os diversos atores e as redes em que se situam.

Por isso, como se diz no mesmo documento (idem, p. 119), para melhorar o funcionamento do sistema, não basta determinar a delegação do poder para as autoridades locais. É preciso conceder uma atenção especial às conexões, à interatividade e às relações de interdependência, uma vez que elas podem gerar efeitos positivos ou negativos em diferentes partes do sistema. A governança pública deve permanecer suficientemente flexível, adaptando-se ao dinamismo e à complexidade do sistema e prosseguindo os objetivos estabelecidos, dentro de um orçamento limitado. Neste sentido, o documento a que temos vindo a fazer referência afirma que uma governança moderna e eficaz, em matéria de educação, apresenta as características seguintes:

Concentra-se nos processos e não nas estruturas. (...) É flexível e capaz de se adaptar à mudança e a acontecimentos imprevistos. (...) Apoia-se no reforço das suas capacidades, na implicação das partes e num diálogo aberto. (...) Requer uma abordagem global à escala do sistema. (...) Tira partido de dados probatórios e de trabalhos de investigação com o fim de sustentar a aplicação das políticas e das reformas. (...) (idem, p. 119)

De acordo com o mesmo relatório, verifica-se em muitos sistemas de ensino (Austrália, Canadá, Espanha, Finlândia, Hong-Kong (China), Israel, Reino Unido, Singapura e Suécia, por exemplo) um aumento das responsabilidades dos estabelecimentos de ensino na tomada de decisão sobre os programas escolares e a afetação de recursos. Neste contexto, os professores são sobretudo responsáveis pelo conteúdo pedagógico dos diversos cursos e pela escolha dos manuais escolares, repartindo a sua responsabilidade com a direção da escola no que se refere à avaliação e à disciplina escolar.

No seu conjunto, estas medidas tornam o trabalho docente consideravelmente mais exposto ao escrutínio público, incluindo quer as autoridades do Estado, quer as comunidades educativas que servem. Conforme já assinalado por outros autores, este fenómeno tem conduzindo a uma crescente responsabilização pelos resultados escolares dos alunos (MAROY, 2012; AUGUSTO, 2013; LESSARD, \& CARPENTIER, 2015).

Efetivamente, o controlo sobre a profissão docente parece agora concretizar-se através de outras e variadas modalidades que não se esgotam nos dispositivos tradicionais como o recrutamento e o ingresso na carreira, a avaliação de desempenho e de progressão. Este fenómeno é sinal da progressiva erosão do modo de regulação burocrático-profissional, baseado na "aliança” tácita entre o Estado e os professores (BARROSO, 2005), com a emergência de novos modos de regulação, baseados em dois referenciais principais - o "Estado avaliador” e o “quase-mercado" (MAROY, 2012) - no quadro da difusão mundial da NGP (VERGER \& NORMAND, 2015). 
Nesse sentido, podemos afirmar que as condições de recrutamento, progressão da carreira e a avaliação de desempenho, mesmo que negociadas em concertação social, através dos sindicatos e da administração educativa, já não constituem as peças centrais sobre as quais se vai construindo um novo discurso sobre o profissionalismo docente que é, cada vez mais, exteriormente imposto (CARVALHO E NORMAND, 2018).

\section{Notas}

1. A primeira parte do presente artigo baseia-se numa pesquisa efetuada por Viseu \& Amadeu (2019) produzida no âmbito do projeto "Políticas públicas para a melhoria do ensino médio: socialização científica, tradução e transferência de resultados”, financiado pelo Edital 22/2016 do CNPq.

2. No presente texto suprimiram-se a maior parte das referências para designação formal da legislação portuguesa, atendendo à sua divulgação internacional, mas poderão ser consultadas no relatório indicado.

3. De acordo com o fixado na Portaria n. ${ }^{\circ} 1141$ - D/95, de 15 de setembro "entende-se por habilitação própria aquela que é adquirida através da titularidade de uma licenciatura ou da combinação de um bacharelato com um diploma de estudos superiores especializados que integre uma componente de formação científica, tecnológica, técnica ou artística adequada.” Ainda de acordo com a mesma portaria, “a habilitação própria pode ainda ser adquirida através de uma licenciatura e de um outro curso superior completo que, em conjunto, integrem uma componente de formação científica, tecnologia, técnica ou artística adequada ao conjunto das disciplinas que constituem o grupo.” Por "habilitação suficiente (...) entende-se aquela que é adquirida através da titularidade de um bacharelato ou licenciatura que satisfaça parcialmente os requisitos fixados para as habilitações próprias para esse grupo.”

4. À̀ licenciatura «cabe assegurar a formação de base na área da docência» e «ao segundo ciclo, o mestrado, cabe assegurar um complemento dessa formação que reforce e aprofunde a formação académica, incidindo sobre os conhecimentos necessários à docência nas áreas de conteúdo (...). Cabe igualmente ao segundo ciclo assegurar a formação educacional geral, a formação nas didáticas específicas da área da docência, a formação nas áreas cultural, social e ética e a iniciação à prática profissional, que culmina com a prática supervisionada (Decreto-Lei n. ${ }^{0}$ 79/2014 de 14 de maio).

5. Vale a pena referir que, desde finais dos anos 1900 até meados dos anos 2000 foram reforçados os processos de certificação de qualificação profissional dos professores e que incluíram a definição do grau de licenciatura como habilitação mínima de aquisição da habilitação profissional em todos os níveis de ensino; a criação do Conselho Nacional de Avaliação do Ensino Superior (que estabeleceu os princípios do sistema de avaliação e acompanhamento do ensino superior; foi aprovada a Lei Orgânica do Instituto Nacional de Acreditação da Formação de Professores (INAFOP), entidade responsável por garantir a qualidade dos cursos de formação inicial de professores (entretanto extinta em 2002).

6. «Docentes do quadro” são docentes com um contrato por tempo indeterminado e que são, para todos, os efeitos funcionários públicos); os “contratados” são docentes que têm contratos de trabalho durante um ano.

7. Em 2011 Portugal assinou um memorando de entendimento com a Comissão Europeia, o Banco Central Europeu e o Fundo Monetário Internacional (conhecida como "Troika”) que estabeleceu as condições para a concessão de um empréstimo financeiro. Para cumprir as condições estabelecidas para o empréstimo, em apenas três anos, Portugal concretizou medidas de ajuste estrutural, com assinaláveis cortes na despesa pública, incluindo a educação entre outras áreas sociais (ver, por exemplo, EPRS, 2013; Reis, 2014).

8. Desde que esses contratos tenham sido relativos a horários anuais e completos.

9. A categoria de professor titular ficou reservada a professores que desempenhassem funções de coordenação de anos, ciclos, cursos, departamentos ou funções de direção em centros de formação das associações de escolas, incluindo ainda funções de elaboração e correção de provas nacionais de acesso à carreira.

10. Ver, por exemplo, as notícias publicadas online a 8 de março de 2008 no Jornal Público em https://www.publico.pt/2008/03/08/portugal/noticia/maior-manifestacao-de-sempre-na-educacao-pintou-lisboa-denegro-1322010; no semanário Expresso https://expresso.sapo.pt/dossies/dossiest_actualidade/dos_crise_educacao/100-mil-professores-narua=f262140\#gs.twPYRso; na revista Visão em http://visao.sapo.pt/actualidade/sociedade/maior-manifestacao-desempre=f521190. 


\section{Referências}

AFONSO, N. Avaliação e desenvolvimento organizacional da escola. Meta: Avaliação, v. 1, n. 2, p. 150-169, 2009. Disponível em: <http://revistas.cesgranrio.org.br/index.php/metaavaliacao/article/view/40>. Acesso em: 20 de fev. 2020.

AUGUSTO, M. Os últimos dez anos de governo em Minas Gerais: a política de resultados e o trabalho docente. Educ. Soc., v. 34, n. 125, p. 1269-1285, 2013. Disponível em: <http://www.scielo.br/scielo.php?script=sci_ arttext\&pid=S0101-73302013000400013\&lng=pt\&tlng=pt $>$. Acesso em: 20 de fev. 2020.

ASSUNÇÃO, A. A; OLIVEIRA, D. A. Intensificação do trabalho e saúde dos professores. Educ. Soc., v. 30, n. 107, p. 349-372, 2009. Disponível em <http://www.scielo.br/scielo.php?pid=S010173302009000200003\&script=sci_abstract\&tlng=pt>. Acesso em: 20 de fev. 2020.

AZEVEDO, J.; VEIGA, J. J.; RIBEIRO, D. As motivações a preocupações dos professores: Apresentação dos resultados de um inquérito. Vila Nova de Gaia: Fundação Manuel Leão, 2016.

BARROSO, J. A emergência do local e os novos modos de regulação das políticas educativas. Educação: temas e problemas, n. 12 e 13, p. 13-25, 2013. Disponível em: < http://www.revistas.uevora.pt/index.php/ educacao/article/view/11>. Acesso em: 20 de fev. 2020.

BARROSO, J. A formação dos professores e a mudança organizacional das escolas. In: FERREIRA, N. S. C (Org.). Formação continuada e gestão da educação. São Paulo: Cortez, 2006, p. 117-144.

BARROSO, J. A transversalidade das regulações em educação. Modelo de análise para o estudo das políticas educativas em Portugal. Educ. Soc., v. 39, n. 145, p. 1075-1097, 2018. Disponível em: <http://www.scielo. br/scielo.php?script=sci_abstract\&pid=S0101-73302018000401075\&lng=pt\&nrm=iso $>$. Acesso em: $20 \mathrm{de}$ fev. 2020.

BARROSO, J. O Estado, a educação e a regulação das políticas públicas. Educ. Soc., v. 26, n. 92, pp. 725-751, 2005. Disponível em: <http://www.scielo.br/scielo.php?pid=S0101-73302005000300002\&script=sci_ arttext>. Acesso em: 20 de fev. 2020.

CARVALHO, L. M.; VISEU, S.; GONÇALVES, C. Bridging worlds and spreading light: Intermediary actors and the translation of knowledge for policy in Portugal. In: Pettersson, D; Mølstad, C. (Eds.), Numbers and Knowledge in Education: New Practices of Comparison, Quantification and Expertise. Routledge, 2019, p. 111-126.

CARVALHO, L.; NORMAND, R. Introduction. In: NORMAND, R., Liu, M., CARVALHO, L. M., OLIVEIRA, D. A.; LEVASSEUR, L. (Eds.). Education Policies and the Restructuring of the Educational Profession: Global and Comparative Perspectives. Springer, 2018, p. 1-12.

COMISSÃO EUROPEIA/EACEA/EURYDICE. A Carreira Docente na Europa: Acesso, Progressão e Apoios. Relatório Eurydice. Luxemburgo: Serviço de Publicações da União Europeia, 2018.

COMISSÃO EUROPEIA/EACEA/EURYDICE. Funding of education in Europe 2000-2012: the impact of the economics crisis. Relatório Eurydice. Luxemburgo: Serviço de Publicações da União Europeia, 2013b.

COMISSÃO EUROPEIA/EACEA/EURYDICE. Números-Chave sobre os Professores e os Dirigentes Escolares na Europa. Edição de 2013. Relatório Eurydice. Luxemburgo: Serviço de Publicações da União Europeia, 2013a.

CONSELHO NACIONAL DE EDUCAÇÃO. Estado da Educação 2017. Lisboa: Conselho Nacional de Educação, 2018.

CONSELHO NACIONAL DE EDUCAÇÃO. Estudos. Regime de Seleção e Recrutamento do Pessoal Docente da Educação Pré-escolar e Ensinos Básico e Secundário. Lisboa: Conselho Nacional de Educação, 2019. 
CONSELHO NACIONAL DE EDUCAÇÃO. Formação inicial de educadores e professores $e$ acesso à profissão. Lisboa: Conselho Nacional de Educação, 2016.

COSTA, E. Contributos para uma análise cognitiva da política de avaliação de professores. Sísifo. Revista de Ciências da Educação, v. 4, p. 49-58, 2007. Disponível em: < http://sisifo.ie.ulisboa.pt/index.php/sisifo/article/view/75 >. Acesso em: 20 de fev. 2020.

DAY, C. A reforma da escola: profissionalismo e identidade dos professores em transição. In: Flores, M.; Viana, I. (Org.). Profissionalismo docente em transição: as identidades dos professores em tempos de mudança. Braga: Universidade do Minho, 2007, p. 48-63.

DGEC \& DSEE. Perfil do Docente 2016/2017. Lisboa: Direção-Geral de Estatísticas da Educação e Ciência, 2017.

ESTEVES, M.; RODRIGUES, A.; SILVA, M. L.; CARITA, A. Para pensar a educação em Portugal: a formação dos professores. Grupo Economia e Sociedade. Pensar a Educação. Portugal. Lisboa: EDUCA, 2015, p. 1-33.

EUROPEAN PARLIAMENTARY RESEARCH SERVICE (2013). Social dimension of austerity measures. Cases of four EU countries in receipt of financial assistance. Briefing European Parliamentary Research Service, 10/12/2013. Disponível em: <http://epthinktank.eu/tag/eprs-briefings/page/6/>. Acesso em: 20 de fev. 2020.

EUROPEAN UNION. Education and Training. Monitor 2019. Luxembourg: Publications Office of the European Union, 2019. Disponível em: <https://ec.europa.eu/education/sites/education/files/documentlibrary-docs/volume-1-2019-education-and-training-monitor.pdf>. Acesso em: 20 de fev. 2020.

FLORES, M. A. Da avaliação de professores: Reflexões sobre o caso português. Revista Iberoamericana de Evaluación Educativa, v. 2, n. 1, p. 239-256, 2009. Disponível em: < https://revistas.uam.es/index.php/riee/article/view/4579 >. Acesso em: 20 de fev. 2020.

GOMES, A. R.; PEIXOTO, A.; PACHECO, R.; SILVA, M. Stress ocupacional e alteração do Estatuto da Carreira Docente português. Educação e Pesquisa, v. 38, n. 2, p. 357-371, 2012. Disponível em: $<$ http://www.scielo.br/scielo.php?script=sci_arttext\&pid=S1517-97022012000200006 >. Acesso em: $20 \mathrm{de}$ fev. 2020.

HARGREAVES, A. A profissão de ensinar, hoje. In: Adão, A.; Martins, E. (org.). Os professores: identidades (re)construídas. Lisboa: Edições Universitárias Lusófonas, 2004, p. 13-36.

JACINTO, M. Esferas de influência na avaliação de professores: Das políticas avaliativas às conceções $e$ práticas de avaliação numa escola básica e secundária. Tese de doutoramento apresentada à Universidade de Lisboa. Lisboa: Universidade de Lisboa, 2013.

LESSARD, C.; CARPENTIER, A. Politiques éducatives: la mise en ouvre. Paris: Puf, 2015.

LIU, S.; ONWUEGBUZIE, A. J. (2012). Chinese Teachers' Work Stress and Their Turnover Intention. International Journal of Educational Research, 53, p. 160-170, 2012. Disponível em: <https://www. sciencedirect.com/science/article/pii/S0883035512000237?via\%3Dihub>. Acesso em: 20 de fev. 2020.

MALET, R. Former, réformer, transformer la main d'oeuvre enseignante? Politiques comparées et expériences croisées anglo-américaines. Éducation et sociétés, v. 23, n. 1, p. 91-122, 2009. Disponível em: $<$ https://www.cairn.info/revue-education-et-societes-2009-1-page-91.htm\#>. Acesso em: 20 de fev. 2020.

MAROY, C. Les évolutions du travail enseignant en France et en Europe: facteurs de changement, incidences et résistance dans l'enseignement secondaire. Revue Française de Pédagogie, v. 155, p. 111-142, 2006. Disponível em: <https://journals.openedition.org/rfp/273>. Acesso em: 20 de fev. 2020.

MAROY, C. Towards post-bureaucratic modes of governance: A European perspective. In: WALDOW, F.; STEINER-KHAMSI, G. (Eds.). Policy Borrowing and Lending in Education. London: Routledge, 2012, p. 62-79. 
MAROY, C.; MANGEZ, C. Rationalisation de l'action publique ou politisation de la connaissance? Revue Française de Pédagogie, v. 164, p. 87-90, 2008. Disponível em: <https://journals.openedition.org/rfp/2136 >. Acesso em: 20 de fev. 2020.

MEIRA, M. A burocracia eletrónica: Um estudo sobre as plataformas electrónicas na administração escolar. Tese de doutoramento apresentada à Universidade do Minho. Braga: Universidade do Minho, 2017.

MONTGOMERY, C.; RUPP, A. A. Meta-Analysis for Exploring the Diversity Causes and Effects of Stress in Teachers. Canadian Journal of Education, v. 28, n. 3, p. 458-486, 2005. Disponível em: <https://www.jstor.org/stable/4126479?seq=1>. Acesso em: 20 de fev. 2020.

MORAIS, J. Políticas públicas de recrutamento de professores Desafios a partir da seleção de docentes pelas escolas TEIP. Tese de doutoramento apresentada à Universidade de Lisboa. Lisboa: Universidade de Lisboa, 2016.

NÓVOA, A. Entre a formação e a profissão: ensaio sobre o modo como nos tornamos professores. Currículo sem Fronteiras, v. 19, n. 1, p. 198-208, 2019. Disponível em: < http://www.curriculosemfronteiras.org/vol19iss1articles/novoa.pdf >. Acesso em: 20 de fev. 2020.

NUNES, C.; RODRIGUES, P. A (in)evitabilidade da avaliação do desempenho docente em Portugal: processos, tensões e desafios1. Avaliação em educação: olhares sobre uma prática social incontornável. Pinhais: Editora Melo, 2011, p. 167-184.

OCDE. PISA 2015 Results (Volume IV). Paris: OCDE, 2015. Disponível em: <http://doi.org/10.1787/9789264270282-en.> Acesso em: 20 de fev. 2020.

PEREIRA, I. B. Avaliação do desempenho docente e conflitos profissionais: ensaio de um enquadramento $e$ exploração de evidências sobre o caso português. Lisboa: CIES e-Working Papers, 2009. Disponível em: $<$ https://repositorio.iscte-iul.pt/handle/10071/1256>. Acesso em: 20 de fev. 2020.

POCINHO, M.; CAPELO, M. Vulnerabilidade ao stress, estratégias de coping e autoeficácia em professores portugueses. Educação e Pesquisa, v. 35, n.2, p. 351-367, 2009. Disponível em: < http://www.scielo.br/scielo.php?pid=S1517-97022009000200009\&script=sci_abstract\&tlng=pt $>$. Acesso em: 20 de fev. 2020.

REIS, J. (coord). A Economia Política do Retrocesso. Crise, Causas e Objectivos. Coimbra: Almedina/CES, 2014.

RUIVO, J. et al. Ser professor: satisfação profissional e papel das organizações de docentes: um estudo nacional. Castelo Branco: Instituto Politécnico de Castelo Branco, 2006.

SILVA BODIÃO, I.; FORMOSINHO, J. A profissionalidade docente na educação básica em Portugal: depoimentos de alguns professores. Educação e Pesquisa, v. 36, n. 1, p. 403-418, 2010. Disponível em: <http://www.scielo.br/scielo.php?script=sci_arttext\&pid=S1517-97022010000100014 >. Acesso em: 20 de fev. 2020.

SKAALVIK, E. M.; SKAALVIK, S. Teacher stress and teacher self-efficacy as predictors of engagement, emotional exhaustion, and motivation to leave the teaching profession. Creative Education, 7(13), 17851799, 2016. Disponível em: < https://www.scirp.org/journal/paperinformation.aspx?paperid=69852>. Acesso em: 20 de fev. 2020.

STOLEROFF, A., \& PEREIRA, I. Teachers' unions and the transformation of employment relations in public education in Portugal. Transfer: European Review of Labour and Research, 14(2), p.313-331, 2008. Disponível em <https://doi.org/10.1177/102425890801400210>. Acesso em: 20 de fev. 2020.

VERGER, A.; NORMAND, R. Nueva gestión pública y educación: Elementos teóricos y conceptuales para el estudio de un modelo de reforma educativa global. Educação e Sociedade, v. 36, n. 132, p. 599-622, 2015. Disponível em: $\quad$ http://www.scielo.br/scielo.php?script=sci_arttext\&pid=S010173302015000300599\&lng=en\&nrm=iso\&tlng=es > Acesso em: 20 de fev. 2020. 
VISEU, S.; AMADEU, R. Políticas educativas e profissão docente em Portugal (2008-2018). Relatório de projeto Políticas públicas para a melhoria do ensino médio: socialização científica, tradução e transferência de resultados - "Meta1- Ação 1.2 - Estado da arte e produção do conhecimento". Lisboa: Instituto de Educação da Universidade de Lisboa, 2019.

VISEU, S.; CARVALHO, L. M. Changes in school governance and the reshaping of head teachers' roles and identities in Portugal. In: NORMAND, R., Liu, M., CARVALHO, L. M., OLIVEIRA, D. A.; LEVASSEUR, L. (Eds.). Education Policies and the Restructuring of the Educational Profession: Global and Comparative Perspectives. Springer, 2018, p. 57-70.

WILLIAMSON, B. Digital education governance: data visualization, predictive analytics, and 'real-time' policy instruments. Journal of Education Policy, v. 31, n. 2, p. 123-141, 2015. Disponível em: $<$ https://www.tandfonline.com/doi/full/10.1080/02680939.2015.1035758Z>. Acesso em: 20 de fev. 2020.

WORTH, J.; VAN DEN BRANDE, J. Teacher Labour Market in England - Annual Report 2019. Berkshire: National Foundation for Educational Research, 2019.

\section{Correspondência:}

Sofia Viseu: É professora auxiliar no Instituto de Educação da Universidade de Lisboa (IE- ULisboa), onde desenvolve a sua atividade de ensino graduado e pós-graduado em política e administração educacional, coordenando o Mestrado em Educação e Formação, na área de especialização Organização e Gestão da Educação e Formação. Atualmente é presidente do Fórum Português de Administração Educacional e investigadora da Unidade de Investigação e Desenvolvimento em Educação e Formação (UIDEF). As suas publicações mais recentes incidem sobre a regulação da educação, novos atores nas políticas públicas de educação e redes políticas.

E-mail: sviseu@ie.ulisboa.pt

http://orcid.org/0000-0002-0059-9717

João Barroso: É professor catedrático aposentado do Instituto de Educação da Universidade de Lisboa (IEULisboa), tendo exercido as funções de Vice-Reitor da Universidade de Lisboa, entre 2011 e 2013, de Coordenador da Área Estratégica de Ciências Sociais da Universidade de Lisboa, entre 2009 e 2011 e de Presidente do Conselho Diretivo da Faculdade de Psicologia e de Ciências da Educação da Universidade de Lisboa, entre 2005 e 2009. Exerce a atividade de investigação e de docência no domínio da política e da administração da educação sendo autor de uma extensa obra publicada sobretudo em Portugal, Brasil, Espanha, França e Bélgica. Recebeu o Prémio Rui Grácio, atribuído em 1996 pela Sociedade Portuguesa de Ciências da Educação e pela Fundação Calouste Gulbenkian.

E-mail: jbarroso@ie.ulisboa.pt

https://orcid.org/0000-0003-1371-1605

Texto publicado em Currículo sem Fronteiras com autorização dos autores 